\title{
Research on Operation Mechanism of Regional Shared Urban Rail Transit Training Base
}

\author{
Xiaoran Wang \\ Jilin Railway Technology College, Jilin, China
}

Keywords: operation mechanism, regional shared urban, rail transit training base

\begin{abstract}
The construction and operation management of the regional training base for urban rail transit operation management needs to mobilize relevant personnel, funds, equipment and other factors, and it is necessary to establish a long-term mechanism to make these factors play an active role. In the aspect of driving the training base in the school, professional schools should establish a government investment-driven mechanism, a school-enterprise interest-driven mechanism, and a cooperative project selection mechanism. In terms of operational management, it is necessary to establish a coordination mechanism between teaching management and production management, quality control and performance evaluation. It is necessary to establish an information communication mechanism, a talent financing mechanism, and an emotional exchange mechanism.
\end{abstract}

\section{Introduction}

The regional shared training base refers to the establishment of an open, shared and cooperative training base in a certain area. It is based on the regional economy and serves the regional economy. The regional shared training base serves the school's teaching, and is open to the whole society in this domain, maximizing resource sharing, becoming a window for serving the society, a carrier for school-enterprise cooperation, and a platform for combining production, education and research.

According to the 2014 annual report of China Urban Rail Transit, 18 cities have opened urban subways, 29 cities are constructing subway lines, 53 cities have planned urban subway lines, and urban rail transit has entered a period of vigorous development. The great development of the industry has also brought about a new situation in urban rail transit vocational education. In addition to the shortage of urban rail transit related graduates run by the original railway colleges, many non-original railway vocational colleges have launched urban rail transit. Related majors, jointly cultivate a large number of professional skills required for urban rail transit. The construction and operation mechanism of the vocational training base in vocational schools refers to the factors, such as personnel, funds and equipment, which affect the training of the training base during the construction and operation of the training base, and the process that affects the function of these factors. The formation of a long-term mechanism is the institutional guarantee for the construction of a training base and the benign operation.

\section{The Function of Regional Shared Urban Rail Transit Training Base}

The urban rail transit training base starts with the of the "teaching, learning, and doing" integrated teaching mode, including the operational simulation comprehensive training room, the train driving simulation training room, the simulated driving training room, the station control training room, and the depot. Signal Building Training Room, OCC Training Room, Station Business Training Room, Ticketing Training Room, AFC and PSD Disassembly Training Room, PLC Control Training Room, Switching Machine Training Room, Interlocking Equipment Training Room Thirteen training modules, such as the public basic training room, can cover the training of five major post groups, such as driving, crewing, stationing, electromechanical and Tonghao, to realize the seamless docking of enterprise posts.

The construction of urban rail transit training base has a high starting point and advanced equipment. It represents the advanced level of urban rail transit industry development to a certain 
extent. It is fully qualified to become an employee training base for urban rail transit operators and related higher vocational colleges. According to the skill requirements of the urban rail transit operation enterprise post group, the urban rail transit training base has developed a perfect training system. The training base can also provide training for vocational college students who have established urban rail transit related majors and lack of training equipment.

With the vigorous development of the urban rail transit industry in China, the number of higher vocational colleges that have opened urban rail transit related majors in China has also increased. The urban rail transit skills competitions at all levels have also been established. The urban rail transit training base has complete functions, and has the closest driving, driving, passenger transport, electromechanical and signal training equipment systems to the enterprise. It can undertake national rail transit vocational skill competitions at the national and provincial levels.

The urban rail transit training base can undertake the construction of urban rail transit industry management system, urban rail transit enterprise equipment maintenance standards and urban rail transit practitioners' access qualification, urban rail transit trial operation assessment, urban rail transit operation safety assessment and other industries. Management support; provide enterprises with driving organization, train driving, passenger transportation management, mechanical and electrical and signal equipment maintenance and other job efficiency and method improvement measures.

The urban rail transit training base can provide vocational qualifications for professional posts oriented by urban rail transit operation management, urban rail transit electromechanical technology, urban rail transit communication and signal technology, set up assessment modules, establish test questions, and improve The corresponding evaluation system will further promote the occupational skills appraisal of the urban rail transit industry in the region.

\section{The Operation Mode of Regional Shared Urban Rail Transit Training Base}

The urban rail transit training base teaching and training course system is based on the enterprise job skill requirements. The professional course system consists of theoretical + practical courses. The proportion of practical courses is not less than 50\%. All professional teachers complete the practice of Shenyang Metro enterprises and basically reach the front line of enterprises. The skill level of the staff; the construction of the training base truly restores the first-line equipment and work scenes of the enterprise. Each training room can realize the combination of theoretical teaching and practical teaching; the innovative management mode of the training base is managed by professional teachers who are proficient in equipment. And maintenance; the assessment of the pragmatic curriculum is carried out in a theoretical + practical assessment mode, which realizes the integration of teaching and rationality, the integration of teachers, the integration of classrooms, the integration of teaching and research rooms, and the integration of assessment and practice. .

By exploring the operational mechanism of the regional shared urban rail transit training base, which complements the advantages of complementing each other, sharing resources, and benefiting each other, the government and enterprises will formulate a system for the joint construction of training bases. Formulate the "Regulations for the Management of Equipment in Training Room", "Regulations on the Management of Training Teachers", "Code of Training for Trainees", "Regulations on Maintenance of Equipment in Training Room", "Use of Training Room", "Key to the Training Room" It also stipulates the rules and regulations such as the "Regulations on the Safety and Health Management of the Training Room", the "Measures for the Assessment of the Work of Teachers of Training", the "Standards for the Evaluation of Teaching Quality of Training Teachers" and the "Standards for the Training of Trainees". The establishment of a series of rules and regulations is conducive to the standardization, process and standardization of the management, maintenance, maintenance and training of urban rail transit training base training equipment.

According to the actual needs of the post training of urban rail transit operators and the needs of college teachers' practical skills training, a set of targeted training curriculum system, training management system and training implementation system are established. The training course system includes on-the-job training, on-the-job training, professional knowledge and professional 
technical training, management and leadership skills training, and a series of training courses with characteristics of urban rail transit operations; training management system including training system, training policy, training responsibilities, training A series of training-related systems such as information collection feedback and management, training evaluation system, training budget and expense management, training and performance appraisal management; training implementation system includes ensuring the implementation of training system, and effective organization, implementation and tracking of training activities And a set of control processes that reflect, improve, and enhance the value of the training.

\section{Coordination Mechanism of Teaching Management and Training Management}

In the productive training base, teaching and training is a line, and social service is a line, which belongs to two-line operation. Therefore, it is necessary to establish a sound coordination mechanism between teaching management and social service management.

First, you need to establish an organization. Establish a campus training base management committee with a relatively complete professional department or professional group. The composition of the committee can vary according to different political school-enterprise portfolio models, but its ultimate goal is to operate the base in a normal and orderly manner. The committee is guided by the school's functional department.

Second, clarify relevant responsibilities and interests. Within the main framework of the Base Management Committee, schools and enterprises and other stakeholders, on the basis of full consultation, signed a school-enterprise cooperation agreement to clarify the responsibilities, powers and benefits of the cooperation between the school and the enterprise. At the same time, establish corresponding rules and regulations and binding mechanisms. On the one hand, we must ensure the orderly conduct of production, protect the interests of enterprises, and promote the school to actively participate in the training of enterprise employees, undertake the technical research and development tasks of enterprises; In the process of student internship, the teaching function, such as the number of hours of training and guidance tasks, should limit the $40 \%$ of the company's production capacity for practical teaching to ensure the effectiveness of productive training.

Third, implement dual goals and standardized management. The dual goal is the company's development goals and the school's talent development goals. The school and enterprise should improve the enterprise work process and the school training mode according to the actual production and processing requirements of the enterprise, and jointly develop the operation process of the training base. The professional teachers and enterprise technicians will jointly formulate the enterprise production and operation plan and the enterprise employee training plan, and jointly formulate relevant professional project training, comprehensive training and post-training internship plan. At the same time, the introduction of national and industry unified standards, jointly develop enterprise production technology, process flow and quality inspection standards, and according to corporate standards, formulate school personnel training standards and curriculum standards, training standards, and implement standardized management.

Fourth, improve the training management system. Based on the uncertainty of "work" in the training, the teaching management operation of vocational schools should reflect the characteristics of occupation and openness, implement flexible management, and proceed from the actual needs of personnel training, timely adjust the teaching plan and teaching content to meet the society. And the needs of enterprises, such as according to the production cycle of enterprises, large-scale exhibitions and urgent needs of enterprises, etc., can flexibly arrange some students to internships in enterprises and undertake work tasks. At the same time, the "Regulations on Strengthening the Quality Management of Training" and other rules and regulations were formulated. At the same time, we must do a good job in safety education for training, and purchase internship liability insurance for students who participate in training. 


\section{Equilibrium Mechanism of Financial Management and Interest Distribution}

The financial management and benefit distribution of the training base is directly related to the normal operation of the training base, and also to the core interests of both schools and enterprises. As an enterprise department, there are operating costs such as raw materials, equipment maintenance costs, and student salaries; as a practical teaching place, there are also training expenses such as training consumables and instructor class hours.

First of all, it is necessary to formulate management measures for training funds. According to the school-enterprise cooperation agreement, the funds used for training will be managed in accordance with the principles of unified planning, separate accounting, and special funds. Strictly implement the budget for training and earnestly calculate the cost of training.

Second, we must clarify the relevant relationship of interest distribution. The operation of the training base inevitably involves various benefits distribution issues. Nowadays, many vocational schools use the method of "cost offset" and "disbursement of benefits" to blur the relationship of interest distribution. The author believes that this is only an expedient measure. In order to truly achieve a benign operation, the training base must clarify various interests. It is necessary to establish a complete financial base system for training bases, mainly for consumables and enterprise technicians of student training programs. The training instruction time fee and the salary for participating in the construction of the teaching curriculum shall be included in the school's running cost. The enterprise shall pay a certain amount of remuneration to the students participating in the post production pay a certain rent to the venue and equipment provided by the school, and equipment. The maintenance costs of the maintenance and the site's water and electricity are all included in the production costs of the enterprise. In this way, the profit generated by the training base products, or the economic benefits generated by the external technical service and skill training appraisal, can only be allocated. In the end, both schools and enterprises should clearly define the distribution of benefits through consultation.

Third, it is necessary to establish a system for the operation, maintenance and management of training equipment and facilities. The procurement of equipment should be openly tendered, centralized procurement, unified management of fixed assets in schools, and full-process management of fixed asset purchases. The training room of the urban rail transit training base uses yellow marking lines to identify the equipment and article areas; paste the rules and regulations of the training room on the eye-catching wall, so that every student and teacher can clearly see and can bring the rules and regulations down. To the actual situation; use the bulletin board to indicate the operation flow chart of each important instrument and equipment; use the reminder board to remind the trainees of the necessary training operation points, purpose requirements, precautions, and assessment rules. In the specific training process, the trainees are required to check in when they are trained. After the training, the trainees should organize the training equipment as required, place the equipment in the designated place of the mark, and fill in the record of the use of the equipment items in time. After the training is completed, the training room will be cleaned up, the cleaning standards will be established, and the responsibility will be implemented. By consistently adhering to $5 \mathrm{~S}$ management, we will guide all levels of personnel to develop good habits, so that the clean and orderly training room becomes the norm of daily behavioral norms, and at the same time improve the quality of personnel at all levels, and thus the management level of the training room.

\section{Conclusions}

The good operational mechanism and management mode of the regional shared urban rail transit training base will be utilized to improve the utilization rate of training equipment, maximize resource sharing, enhance the school's running strength, and expand social influence. Through the shared construction of the government and enterprise schools of the urban rail transit training base, a synergistic effect is formed, thereby improving the social and economic benefits of vocational education in the urban rail transit industry. 


\section{Acknowledgement}

The thesis is the result of the Higher education research project of JiLin Provincial Association of Higher Education in 2018, "Research on the construction of Practice training base for Urban Rail Transit based on Regional Sharing" (project number: JGJX2018D541)

\section{References}

[1] Jin Yan. Research on the Construction of Lianyungang Regional Shared Logistics Training Base [J]. Logistics Engineering and Management, 2014, (9): 239-241.

[2] Xu Xuefang.5S Management and Laboratory Management Research in Higher Vocational Colleges [J]. Enterprise Technology and Development, 2010, (18):219-220,231.

[3] Chen Wei. Application of Process Management in Laboratory Quality Management [J]. Science and Technology Guide, 2013, (17): 32, 57.

[4] Zhu Wanping, Wu Jing. Thinking and Practice of the Professional Construction of Urban Rail Transit Operation Management [J]. Vocational and Technical Education, 2009.18

[5] Yu Jing, Liu Hua. Practice and thinking on the construction of transportation practice base [J]. Coal Higher Education, 2002.63 